\title{
ALTAS HABILIDADES NO ENSINO EPT E REGULAR: UMA REVISÃO DOS ÚLTIMOS CINCO ANOS
}

\section{ARTIGO ORIGINAL}

RIBEIRO, Edivan Charlton do Nascimento ${ }^{1}$, FECURY, Amanda Alves ${ }^{2}$, OLIVEIRA, Euzébio de ${ }^{3}$, DENDASCK, Carla Viana ${ }^{4}$, DIAS, Claudio Alberto Gellis de Mattos ${ }^{5}$

RIBEIRO, Edivan Charlton do Nascimento. Et al. Altas habilidades no ensino EPT e regular: uma revisão dos últimos cinco anos. Revista Científica Multidisciplinar Núcleo do Conhecimento. Ano. 07, Ed. 01, Vol. 04, pp. 111-130. Janeiro de 2022. ISSN: 2448-0959, Link de acesso:

https://www.nucleodoconhecimento.com.br/educacao/habilidades-no-ensino

${ }^{1}$ Físico com habilitação em Matemática, Especialista em Docência do Ensino Superior (CETE) e em Tecnologias na Educação (PUC RJ). Discente do Programa de PósGraduação em Educação Profissional e Tecnológica (PROFEPT IFAP).

2 Biomédica, Doutora em Doenças Tropicais, Professora e pesquisadora do Curso de Medicina do Campus Macapá, Universidade Federal do Amapá (UNIFAP).

${ }^{3}$ Biólogo, Doutor em Doenças Tropicais, Professor e pesquisador do Curso de Educação Física da, Universidade Federal do Pará (UFPA).

4 Teóloga, Doutora em Psicanálise Clínica. Atua há 15 anos com Metodologia Científica ( Método de Pesquisa) na Orientação de Produção Científica de Mestrandos e Doutorandos. Especialista em Pesquisas de Mercado e Pesquisas voltadas à área da Saúde. Doutoranda em Comunicação e Semiótica (PUC SP).

${ }^{5}$ Biólogo, Doutor em Teoria e Pesquisa do Comportamento, Professor e pesquisador do Curso de Licenciatura em Química do Instituto de Ensino Básico, Técnico e Tecnológico do Amapá (IFAP) e do Programa de Pós Graduação em Educação Profissional e Tecnológica (PROFEPT IFAP).

RC: 105196

Disponível em: https://www.nucleodoconhecimento.com.br/educacao/habilidades-no-ensino 


\section{RESUMO}

A inclusão escolar é um movimento que busca alcançar pessoas que estão fora do contexto escolar devido sua condição diferente. O termo "necessidades especiais" é amplo e envolve muitos fatores. Segundo a legislação é aplicável a qualquer ser humano que tenha impedimento de natureza física, mental, intelectual e/ou sensorial, impedindo sua participação na vida cotidiana e escolar. O conceito "Altas habilidades / Superdotação" ainda é discutível. O mais atual, adotado pela nossa legislação, se refere ao desempenho do indivíduo em sua área de interesse, demonstrando capacidade acima da média. $O$ objetivo deste trabalho foi fazer uma revisão bibliográfica sobre altas habilidades no ensino EPT e regular presentes em publicações nos últimos cinco anos. Foi realizada uma revisão bibliográfica sobre altas habilidades/Superdotação, em língua portuguesa, em bases de dados de pesquisa como Scientific Electronic Library Online - SciELO e Google Acadêmico, entre 2017 e 2021. A inclusão é um processo que requer uma mudança de atitude em relação às pessoas que são consideradas diferentes. Na educação esse movimento começa a ganhar espaço nas escolas, e a educação inclusiva se torna, devagar, uma realidade. Nesse contexto, as pessoas com indicadores de AH/SD sofrem dos mesmos problemas, com o agravante de serem considerados alunos sem dificuldade (e com facilidade) de aprendizagem. $O$ processo de ensino necessita de adequações de processos, de materiais e de formação adequada para todos os professores. $\mathrm{Na}$ Educação Profissional os problemas quanto a identificação e atendimento desse público parece ser semelhante ao da escola regular. outras modalidades de ensino.

Palavras-chave: Altas Habilidades, Superdotação, Inclusão, Ensino, EPT.

\section{INTRODUÇÃO}

O termo inclusão está relacionado com a atitude de incluir o que está fora de um determinado contexto, grupo (BELL-RODRíGUEZ, 2020). A inclusão escolar é um movimento que busca alcançar pessoas que estão fora do contexto escolar devido 
sua condição diferente. Não apenas a sua inserção, mas a oferta de condições para o seu desenvolvimento total, quebrando barreiras físicas, de atitudes, de pré-conceitos e/ou arquitetônicas (estrutura física de acesso) (MANTOAN, 2003).

No Brasil, depois da mobilização de grupos e entidades em prol dos direitos e dignidade das pessoas, a inclusão é garantida pela legislação. Na educação, ela é realizada pela inserção em sala regular. Para que a aprendizagem seja garantida é oferecido a esse aluno, no contra turno, o atendimento especializado, visando atender suas necessidades. Entretanto parece haver ainda muito o que estruturar no espaço escolar, em todas as áreas, para tornar este processo melhor consolidado (SILVA e CARVALHO, 2017).

Pessoas com deficiência, segundo a legislação, são aquelas impedidas por razões físicas, mentais, intelectuais ou sensoriais, de participar plenamente da vida social de maneira equalitária com as outras pessoas (BRASIL, 2015).

O termo "necessidades especiais" é amplo e envolve muitos fatores. Segundo a legislação é aplicável a qualquer ser humano que tenha impedimento de natureza física, mental, intelectual e/ou sensorial, impedindo sua participação na vida cotidiana e escolar. São restrições e limitações que afetam o pleno desenvolvimento da pessoa, envolvendo todos os aspectos de sua vida diária. Dentro do contexto escolar está relacionado a uma diferenciação no ritmo de aprendizagem perante ao que se considera normal. Qualquer um que esteja fora desse padrão é enquadrado neste termo, seja pela dificuldade ou pela facilidade na aprendizagem (CNE/CEB, 2009; BRASIL, 2015).

A definição de inteligência pode ser complexa e com muitas vertentes. Está além do que responder corretamente algo, relacionar ou abstrair conteúdo. É algo inerente à pessoa e é influenciada pelo meio em que vive e a sua genética. Não é restrita ao contexto escolar, mas ao desempenho a várias outras áreas como, por exemplo, a artística e as relações interpessoais (NISTA-PICCOLO et al., 2018). 
O conceito "Altas habilidades/Superdotação" ainda é discutível. O mais atual, adotado pela nossa legislação, se refere ao desempenho do indivíduo em sua área de interesse, demonstrando capacidade acima da média, criatividade, envolvimento na aprendizagem. Abrange a área acadêmica, intelectual, criativa, liderança e/ou outras (MARTELLI, 2017).

Para identificarmos pessoas com indicadores de altas habilidades/superdotação ainda costumam-se usar testes que buscam "medir" a inteligência (testes de quociente de inteligência - QI), muito criticados por limitar ou privilegiar determinadas áreas do conhecimento. Com a mudança da percepção do que é inteligência, onde se observa outros potenciais, utiliza-se as escalas de características comportamentais. No Brasil a escala mais utilizada é a de Renzulli. Ela mede três grupos de comportamentos: interesse, empenho e criatividade (PÉREZ, 2009).

O Núcleo de Atendimento às Pessoas com Necessidades Educacionais Específicas (NAPNE) foi criado para atendimento dos alunos com necessidades educativas especiais matriculados nas redes dos institutos federais. É de sua responsabilidade a implantação e funcionamento dentro da perspectiva da educação inclusiva e do respeito às diferenças. Deve criar condições de ingresso, permanência e conclusão em seus cursos dos alunos público alvo da educação inclusiva. Esse tipo de núcleo foi idealizado pelo MEC através da Secretaria de Educação Profissional e Tecnológica do Ministério da Educação (SETEC/MEC) (IFRN, 2021).

A educação técnica e tecnológica se integra ao sistema de ensino e, por conseguinte, está vinculado às leis que o regem. As pessoas com indicadores de altas habilidades/superdotação, com suas particularidades, estão inseridas na política de educação inclusiva e por essa situação necessitam de atendimento educacional especializado. A educação especial se realiza em todos os níveis, etapas e modalidades de ensino, então a Educação Profissional e Tecnológica não pode se furtar a atender esse público, buscando desenvolver todo o potencial do mesmo implementando, através de seus NAPNEs, políticas de atendimento (BRASIL, 2008). 


\section{OBJETIVO}

Fazer uma revisão bibliográfica sobre altas habilidades no ensino EPT e regular presentes em publicações nos últimos cinco anos.

\section{MÉTODO}

Foi realizada uma revisão bibliográfica sobre altas habilidades/Superdotação, em língua portuguesa, em bases de dados de pesquisa como Scientific Electronic Library Online - SciELO e Google Acadêmico, entre 2017 e 2021. Para tal utilizou-se as palavras-chave (ou descritores) "Altas Habilidades e Educação", "Altas Habilidades e Ensino", "Superdotação e educação", "Superdotação e ensino", "Altas Habilidades e Educação Profissional Tecnológica", "Superdotação e Educação Profissional Tecnológica". Isso possibilita que a revisão seja feita baseada nas mais atualizadas produções acadêmicas (CAPES, 2012).

Foram utilizados, como critérios de inclusão, artigos com conteúdo que unia Altas habilidades/Superdotação com educação, ensino e/ou Educação Profissional e Tecnológica (EPT), dentro do período limite da revisão. Foram excluídos artigos que não atendiam a esse conteúdo e/ou período de tempo.

\section{RESULTADOS E DISCUSSÃO}

Os resultados e as conclusões dos artigos pesquisados são elencados abaixo, com suas respectivas discussões.

A tabela 1 mostra a quantidade de artigos encontrada por descritor pesquisado e a quantidade de artigos utilizados na revisão. Mostra também os autores e anos das publicações utilizadas. 
Tabela 1 - Quantidade de artigos encontrados e utilizados, de acordo com cada descritor, e seus respectivos autores e anos.

\begin{tabular}{|c|c|c|c|c|}
\hline DESCRITOR & BASE DE DADOS & \begin{tabular}{|c|} 
NÚMERO \\
ARTIGOS \\
ENCONTRADOS
\end{tabular} & \begin{tabular}{|c|} 
NÚMERO \\
ARTIGOS \\
UTILIZADOS
\end{tabular} & AUTOR E ANO DOS ARTIGOS UTILIZADOS \\
\hline \multirow{13}{*}{ Inclusåo } & \multirow{6}{*}{ Google Acadê mico } & \multirow{6}{*}{91.000} & \multirow{6}{*}{ 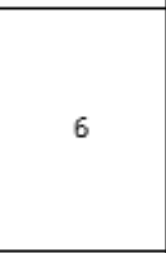 } & (ZERBATO e MENDES, 2018) \\
\hline & & & & (SASSAKI e SILVA, 2018) \\
\hline & & & & (PLETSCH et al., 2017) \\
\hline & & & & (MENDES, 2017) \\
\hline & & & & (MANTOAN, 2017) \\
\hline & & & & (COELHO et al., 2019) \\
\hline & \multirow{7}{*}{ Scielo } & \multirow{7}{*}{1420} & \multirow{7}{*}{7} & (AMARAL, 2019) \\
\hline & & & & (GALHARDO et al., 2020) \\
\hline & & & & (BAPTISTA, 2019) \\
\hline & & & & (ALMEI DA et al., 2019) \\
\hline & & & & (FREITAS e JACOB, 2019) \\
\hline & & & & (SARDAGNA e FROZZA, 2019) \\
\hline & & & & (DARUB et al., 2020) \\
\hline \multirow{4}{*}{$\begin{array}{c}\text { Necessidade } \\
\text { Especiais }\end{array}$} & Google Acadê mico & 28.500 & 1 & (SILVA, 2021) \\
\hline & \multirow{3}{*}{ Scielo } & \multirow{3}{*}{50} & \multirow{3}{*}{3} & (SALVINI et al., 2019) \\
\hline & & & & (FLEIRA e FERNANDES, 2019) \\
\hline & & & & (CASSEMIRO e CAMPOS, 2019) \\
\hline \multirow{5}{*}{$\begin{array}{l}\text { Al tas Habilidades / } \\
\text { Superdotaçåo }\end{array}$} & Google Acadê mico & 6.620 & 1 & (RECHe NEGRINI, 2019) \\
\hline & \multirow{4}{*}{ Scielo } & \multirow{4}{*}{97} & \multirow{4}{*}{4} & (MARTINS et al., 2020) \\
\hline & & & & (MENDONÇA et al ., 2020) \\
\hline & & & & (FAVERI e HEINZLE, 2019) \\
\hline & & & & (STREI ECHEN et al., 2020) \\
\hline \multirow{3}{*}{$\begin{array}{c}\text { Al tas Habilidades / } \\
\text { Superdotaçăo e } \\
\text { Ensino }\end{array}$} & \multirow{2}{*}{ Google Acadê mico } & \multirow{2}{*}{6.050} & \multirow{2}{*}{2} & (MARTINS, 2020) \\
\hline & & & & (REIS e CAPELUNI, 2020) \\
\hline & Scielo & 0 & 0 & +m-n \\
\hline \multirow{6}{*}{$\begin{array}{c}\text { Al tas Habilidades / } \\
\text { Superdotaçăo e } \\
\text { Educaçăo }\end{array}$} & \multirow{2}{*}{ Google Acadê mico } & \multirow{2}{*}{6.420} & \multirow{2}{*}{2} & (PASIAN, 2020) \\
\hline & & & & (CALLEGARI, 2019) \\
\hline & \multirow{4}{*}{ Scielo } & \multirow{4}{*}{17} & \multirow{4}{*}{4} & (OLVEIRA et al., 2021) \\
\hline & & & & (WECHSLER e SUAREZ, 2016) \\
\hline & & & & (OLVEl RA et al., 2020) \\
\hline & & & & (CUNHA e RONDINI, 2020) \\
\hline \multirow{6}{*}{$\begin{array}{l}\text { Altas Habilidades / } \\
\text { Superdotaçåo EPT }\end{array}$} & \multirow{5}{*}{ Google Acadê mico } & & & (BRUNO, 2020) \\
\hline & & & & (ZAGO e RIBEIRO, 2017) \\
\hline & & 128 & 5 & (VOLANTE et al., 2021) \\
\hline & & & & (MONTEIRO e PLÁCIDO, 2020) \\
\hline & & & & (OLVEIRA e FERRÃO, 2021) \\
\hline & Scielo & 0 & 0 & m \\
\hline
\end{tabular}

Fonte: Google Acadêmico.

Os resultados e conclusões dos artigos sobre o descritor "inclusão" com método, autor e ano de cada artigo são mostrados na tabela 2.

RC: 105196

Disponível em: https://www.nucleodoconhecimento.com.br/educacao/habilidades-no-ensino 
Tabela 2 - Resultados e conclusões dos artigos sobre o descritor "inclusão" com método, autor e ano de cada artigo.

\begin{tabular}{|c|c|c|c|}
\hline AUTOR E ANO & $\begin{array}{l}\text { TIPO DE } \\
\text { MÉTODO }\end{array}$ & RESULTADOS & CONCLUSÃO \\
\hline $\begin{array}{l}\text { (ZERBATO e } \\
\text { MENDES, 2018) }\end{array}$ & Quafitio & 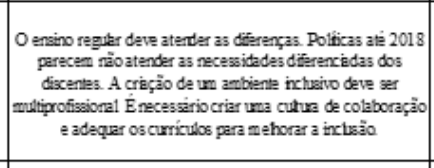 & 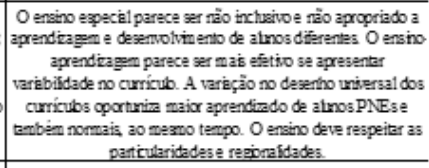 \\
\hline $\begin{array}{c}\text { (S.ASSAKI E SILVA } \\
2018 \text { ) }\end{array}$ & Qualiquentrativo & 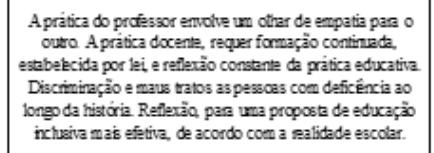 & 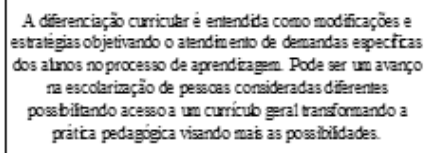 \\
\hline (PLETSCH et a1, 2017) & Qualiquentrativo & 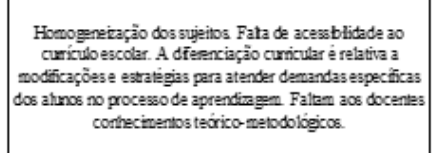 & 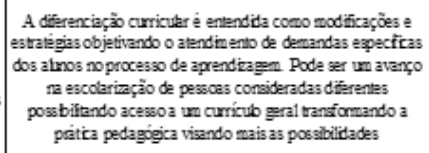 \\
\hline (ARNDES, 2017) & Quafatio & 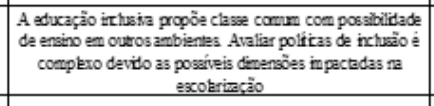 & 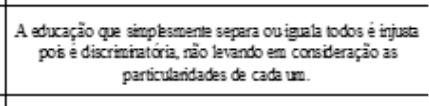 \\
\hline (ALANTOAN 2017) & Quafatio & 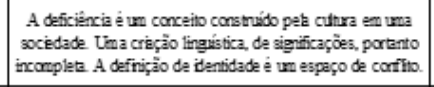 & $\begin{array}{l}\text { A inchualo questiona e denncia a dentidade de un gupo de } \\
\text { pessoas sppresentada por modelos tidos cono verdaderos. }\end{array}$ \\
\hline (COELHO et a1, 2019) & Quafatio & 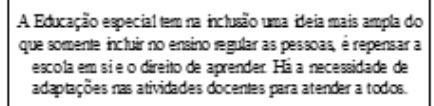 & 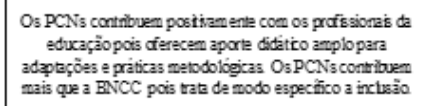 \\
\hline (AMARAL, 2019) & Quafatio & 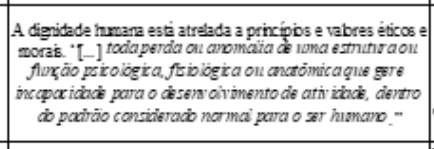 & 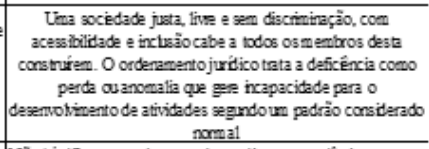 \\
\hline $\begin{array}{l}\text { (GALHARDO et a1. } \\
2020 \text { ) }\end{array}$ & Qualiquentiativo & 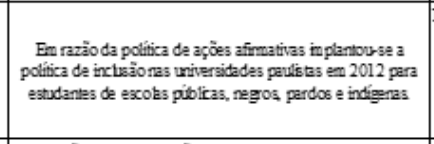 & 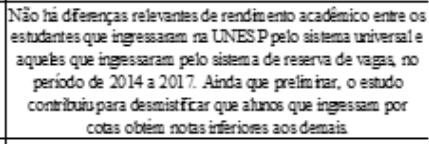 \\
\hline (BAPTISTA 2019) & Quefatio & 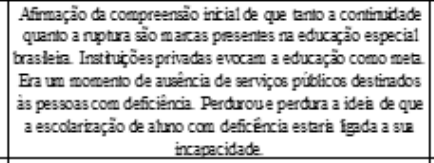 & 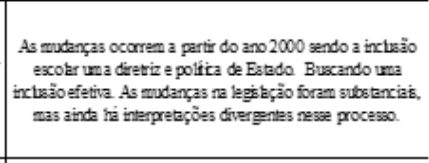 \\
\hline$\frac{(A L M E D A}{2019)}$ & Qualiquentitativo & 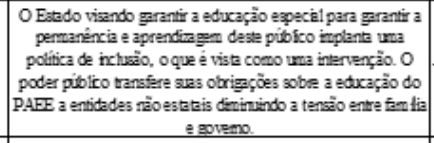 & $\begin{array}{l}\text { As politicas pitblicas de educação especial são consequência de } \\
\text { disputas de forças ente díferentes grupos sockis. }\end{array}$ \\
\hline $\begin{array}{l}\text { (FREIIAS E IACOB, } \\
2019 \text { ) }\end{array}$ & Quafatio & 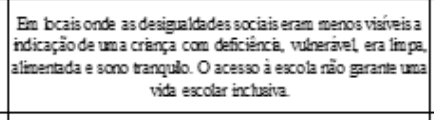 & 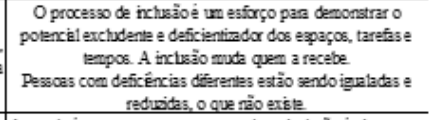 \\
\hline $\begin{array}{l}\text { (SARDAGNAE } \\
\text { FROZZA 2019) }\end{array}$ & Queliquentrativo & 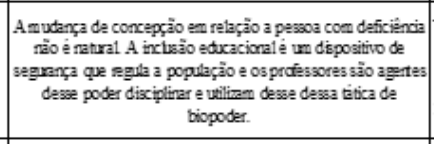 & 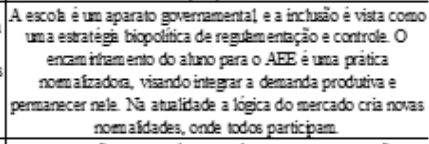 \\
\hline (DARUB et a1, 2020) & Quafatio & 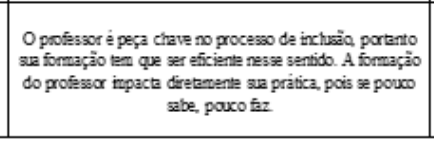 & 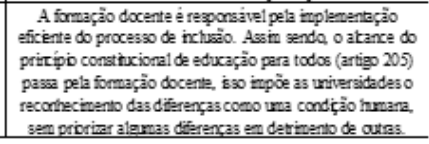 \\
\hline
\end{tabular}

Fontes: (MANTOAN, 2017; MENDES, 2017; PLETSCH et al., 2017; SASSAKI e SILVA, 2018; ZERBATO e MENDES, 2018; ALMEIDA et al., 2019; AMARAL, 2019;

RC: 105196

Disponível em: https://www.nucleodoconhecimento.com.br/educacao/habilidades-no-ensino 
BAPTISTA, 2019; COELHO et al., 2019; FREITAS e JACOB, 2019; SARDAGNA e FROZZA, 2019; DARUB et al., 2020; GALHARDO et al., 2020)[/caption]

A educação inclusiva tem o objetivo de acolher, promover o desenvolvimento e aprendizagem de todos os seus alunos, de forma democrática, portanto destinada a todos (OLIVEIRA et al., 2020). As políticas públicas garantem a inserção do Público Alvo da Educação Especial (PAEE) na rede regular de ensino, mas acredita-se que há outras dificuldades para essa efetivação. Por mais que os professores acreditem na inclusão, o espaço escolar parece ser apenas para a socialização desse público. Isso reflete na aprendizagem de habilidades funcionais e não de conteúdos formais, restringindo o ensino e o conhecimento dos mesmos. Como consequência observase alunos com defasagem escolar (WEIZENMANN et al., 2020).

O aluno tem o direito de ser atendido de forma adequada no ambiente escolar e segundo a educação inclusiva, todos devem aprender juntos. Isso requer a utilização de adequações curriculares como um instrumento que garanta o respeito às diferenças no processo de ensino e de aprendizagem, podendo melhorar o desenvolvimento geral através de estratégias, objetivos e na avaliação do mesmo. As escolas necessitam direcionar seu trabalho respeitando as diversidades individuais, como o ritmo de aprendizagem, e assegurando uma educação de qualidade para todos. Para tornar um ambiente escolar inclusivo, deve-se realizar adaptações curriculares abrangendo as particularidades de cada aluno, recursos didáticos, práticas avaliativas, metodologias e demais meios para uma aprendizagem realmente efetiva. Entretanto essas ações se concretizam com profissionais valorizados, formação continuada que os capacite, apoio pedagógico, salas adequadas, números reduzidos de alunos e salas de recursos multifuncionais (BERTOLDE e LARCHERT, 2020).

A formação de professores aparece como um dos problemas da educação atual, refletindo no ensino. Além da formação outros obstáculos são citados, como a inadequação da estrutura física das escolas, alunos sem diagnósticos e o 
desconhecimento do que seja educação inclusiva. Para que a função de professor seja desenvolvida com qualidade, é necessária competência técnica e pessoal. A inclusão escolar impõe a todos a adaptação diante da diversidade dos alunos, o que implica atenção personalizada, criando oportunidades para o desenvolvimento de todos (FERREIRA e TOMAN, 2020; WEIZENMANN et al., 2020).

A Base Nacional Comum Curricular (BNCC) e os Parâmetros Curriculares Nacionais (PCN) são documentos de referência na educação e orientam a prática docente. $\mathrm{Na}$ educação especial os PCNs têm o objetivo de adaptação curricular buscando uma educação apropriada. Por ser específico orientar melhor a prática docente e o ambiente escolar. A BNCC, por outro lado, não demonstra compromisso e é mais abrangente com a educação especial e a inclusão, não observando a necessária capacitação do profissional da educação e transferindo para cada escola esse compromisso através de seu projeto pedagógico (LIMA, 2020).

A legislação nacional define o $A E E$ como um conjunto de atividades, recursos pedagógicos, e de acessibilidade, organizados de forma institucional e contínua para - PAEE. O atendimento acontece de forma complementar para os alunos com deficiência e transtornos globais de desenvolvimento, e de forma suplementar para os com altas habilidades/superdotação. Essas modalidades apontam o caráter técnico e instrumental desses serviços especializados, e uma formação docente adequada pode contribuir para práticas exitosas junto a esses estudantes. Quando do acesso ao $A E E$, alunos com defasagem idade/série podem apresentar rejeição a esse serviço. Mesmo assim o AEE pode atuar como ferramenta de suporte proporcionando maior nível de aprendizagem, o que é favorável à participação desse público na escola regular (JUNIOR e CIA, 2021).

É necessário o entendimento de quem legalmente tem direito ao ensino especial. Segundo a legislação, os alunos considerados com necessidades especiais são aqueles que apresentam deficiência (com impedimento a longo prazo), os com transtornos globais de desenvolvimento e os com altas habilidades/superdotação. 
Apesar de legalmente restritivo, é um avanço, e os benefícios já foram apontados por estudos (OLIVEIRA et al., 2020).

Tabela 3 - Resultados e conclusões dos artigos sobre o descritor "necessidades especiais" com método, autor e ano de cada artigo.

\begin{tabular}{|c|c|c|c|}
\hline AUTOR E ANO & $\begin{array}{c}\text { TIPODE } \\
\text { MÉTODO }\end{array}$ & RESULT ADOS & CONCLUSÃo \\
\hline (SILVA, 2021) & Qualitativo & $\begin{array}{l}\text { Apesar de es tar na Declaração Univers al dos Direitos do } \\
\text { Homem, o direito de reivind icar cond içóes de aprendizagem e } \\
\text { ação desenvolver-se como pes soa e membro atuante na } \\
\text { soc ieda de, ess a condição não tem sido oferecida. Portador de } \\
\text { neces sid ades especiais é o termo para indicar a pes soa } \\
\text { portadora de deficiência ou de altas hab lilidades/superdotação e } \\
\text { de condutas tipicas. }\end{array}$ & $\begin{array}{l}\text { O professor tomando consciência de sua importância ede seu } \\
\text { desempenho no atendimento dessas pes soas contrubvi para a } \\
\text { transformação da escola em um amb iente de socialização e } \\
\text { integrad or, sem discriminação e fazend o-as se perceberem } \\
\text { como pessoas. }\end{array}$ \\
\hline (SALVINI et al, 2019) & Qualiquantitativo & $\begin{array}{l}\text { Observa-se que a politica pública voltada a edvcação especial } \\
\text { pass cu por restruturação vis ando se ad equar para methor } \\
\text { atender as PAEE. }\end{array}$ & $\begin{array}{l}\text { Ter acesso a infraestrutura básica de acesso afeta positivamente } \\
\text { a possibilid ade de participação no AEE, residir em zona urbana } \\
\text { eleva ess a poss bi iid ade. Observov-se barreiras de acesso ao } \\
\text { AEE por estud antes com defasagem de id ade, mesmo que esse } \\
\text { serviço seja uma ferramenta importante no sev } \\
\text { desenvolvimento. }\end{array}$ \\
\hline $\begin{array}{l}\text { (FLEIRA e } \\
\text { FERNANDES, 2019) }\end{array}$ & Qualiquantitativo & $\begin{array}{l}\text { O uso de material concreto e tecnológico pode favorece a } \\
\text { interação entre aluno e professor, além de permitir a mediação } \\
\text { de conceitos. }\end{array}$ & $\begin{array}{l}\text { A utilização de ma terial concreto e tecnológico favorece a } \\
\text { aprendizagem e a interação na tuma promovendo o processo } \\
\text { de inchsão. }\end{array}$ \\
\hline $\begin{array}{l}\text { (CAS SEMIRO e } \\
\text { CAMPOS, 2019) }\end{array}$ & Qualitativo & $\begin{array}{l}\text { A necessid ade de educar a todos em um padrão comum } \\
\text { demonstrou as diferencas de ritmo e aprendizagem das } \\
\text { pess oas. }\end{array}$ & $\begin{array}{l}\text { A educação inchusiva não é privilégio de alguns, e é justo que } \\
\text { todos usufruam do ensino especial. }\end{array}$ \\
\hline
\end{tabular}

Fontes: (CASSEMIRO e CAMPOS, 2019; FLEIRA e FERNANDES, 2019; SALVINI et al., 2019; SILVA, 2021)

Todo aluno tem o direito a uma educação e atendimento de qualidade na escola com necessidades especiais ou não. Nesse sentido, Mantoan afirma que "[...] todo e qualquer aluno merece uma escola capaz de oferecer-Ihe condições de aprender, na convivência com as diferenças, e que valoriza o que ele consegue entender do mundo e de si mesmo" (OLIVEIRA et al., 2020). Portanto, a Educação Inclusiva pode ser considerada uma concepção de escola que visa o desenvolvimento de respostas educativas que atinjam a todos os alunos (RODRIGUES et al., 2020).

A lei 9394/96 garante a educação básica para a população rural com as adaptações necessárias à sua realidade, de organização curricular própria a calendário escolar diferenciado. Apesar dessa garantia, a educação do campo é um grupo que historicamente sofre com a exclusão e que apresentam características específicas que devem ser respeitadas. Nesse sentido educação do campo e educação inclusiva se assemelham pois objetivam que o aluno tenha acesso a uma educação de RC: 105196

Disponível em: https://www.nucleodoconhecimento.com.br/educacao/habilidades-no-ensino 
qualidade que Ihe possibilite uma atuação crítica na sociedade, mas que não the imponha uma realidade e que respeite e valorize as diferenças (RODRIGUES et al., 2020).

É considerada defasagem idade/série, segundo o Censo Escolar, a diferença em dois anos, ou mais, entre a idade do aluno e a série que deveria estar cursando (SANTOS e SANTOS, 2020). A distorção parece estar ligada às taxas de reprovação dos discentes e ao abandono dos estudos. A falta de investimentos e pesquisas dificulta a equidade e a manutenção do estudante na série correta (FERREIRA e TOMAN, 2020). Observa-se um retrocesso na política de educação no campo, o que pode aumentar essas distorções no meio rural e de comunidades tradicionais (SANTOS e SANTOS, 2020).

A inclusão é um processo no qual a escola e sociedade procuram valorizar as diferenças, habilidades e utilização de diferentes recursos para o desenvolvimento da pessoa. O uso de tecnologias pode ser uma grande aliada para a educação inclusiva, pois é uma ferramenta que cria oportunidades de ensino e de aprendizagem em diversas situações, mediando o desenvolvimento do potencial de cada um (BONNER et al., 2021).

O professor, no contexto da inclusão, age como um mediador que estimula o processo de aprendizagem de todos os alunos, que possam crescer como cidadãos e desempenhar suas tarefas com qualidade para seu crescimento pessoal e profissional. Nesse contexto é o profissional da diferença, mas é necessário que este compreenda e se engaje com a causa, pois é peça chave na perspectiva da educação inclusiva (JESUS et al., 2019).

A tabela 4 mostra os resultados e conclusões dos artigos sobre o descritor "altas habilidades / superdotação" com método, autor e ano de cada artigo 
Tabela 4 - Resultados e conclusões dos artigos sobre o descritor "altas habilidades / superdotação" com método, autor e ano de cada artigo.

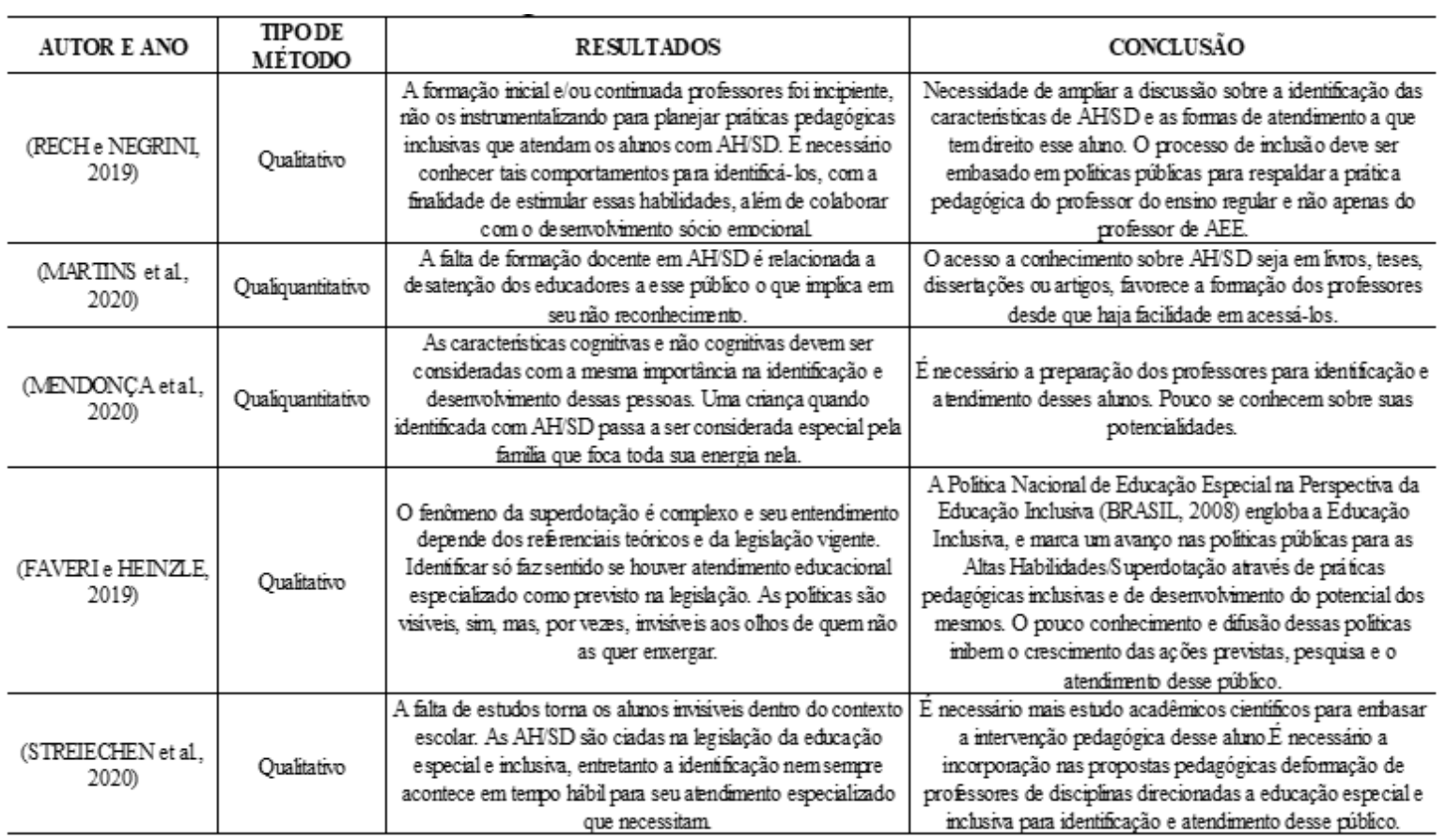

Fontes: (FAVERI e HEINZLE, 2019; RECH e NEGRINI, 2019; MARTINS et al., 2020; MENDONÇA et al., 2020; STREIECHEN et al., 2020)

Os artigos encontrados utilizando os descritores "Altas Habilidades / Superdotação e Ensino" e "Altas Habilidades / Superdotação e Educação", seus autores e anos, são mostrados na tabela 5 .

RC: 105196

Disponível em: https://www.nucleodoconhecimento.com.br/educacao/habilidades-no-ensino 
Tabela 5 - Resultados e conclusões dos artigos sobre os descritores "Altas Habilidades / Superdotação e Ensino" e "Altas Habilidades / Superdotação e Educação", com método, autor e ano de cada artigo.

\begin{tabular}{|c|c|c|c|}
\hline AUTOR E ANO & $\begin{array}{c}\text { TIPODE } \\
\text { MÉTODO }\end{array}$ & RESULTADOS & CONCLUUSÃo \\
\hline (MARTINS, 2020) & Qualiquantitativo & $\begin{array}{c}\text { Conhecimento insuficiente sobre esse público por parte dos } \\
\text { professores do ensino regular quanto de AEE, devido a } \\
\text { ausência de formação docente. A identificação deve envolver } \\
\text { míltiplos critérios } \\
\text { Na aplicação de testes, os destinados a mensurar a inte ligência } \\
\text { não costumam ser práticos à escola. }\end{array}$ & $\begin{array}{l}\text { O desenvokimento das potencialidades da pessoa com AHSD } \\
\text { é atrelada as condições ambientais, deve ser estimulante e } \\
\text { desafiador. A limitação dos testes e o reconhecimento da } \\
\text { superdotação como fenômeno mullidimensional, a tornou } \\
\text { complexa pa 1a confirmar a superdotação baseado em ưm único } \\
\text { teste. }\end{array}$ \\
\hline $\begin{array}{c}\text { (REIS e CAPELLINI, } \\
2020)\end{array}$ & Qualiquantitation & $\begin{array}{l}\text { Observa-se que ter AHSD é considerada uma condição } \\
\text { vantajosa, o que gera a crença equivocada. A avaliação da } \\
\text { criatividade ainda não encontra consenso na literatura. }\end{array}$ & $\begin{array}{l}\text { Altas Habilidades S uperdotação é condição de diversidade e } \\
\text { assim como as demais nessa condição requer o AFE. } \\
\text { Resultados de auto avaliações podemapresentar subavaliações } \\
\text { dependendo do estado doa ahrno. Estratégias de } \\
\text { enriquecimento curricular devem ser ofertado a todos os ahnos } \\
\text { para seu enriquecimento. }\end{array}$ \\
\hline (PASIAN, 2020) & Qualitativo & $\begin{array}{c}\text { Não se discute as causas das AHSD e sim uma terminologia } \\
\text { que possa descreve-ha adequadamente A educação para todos } \\
\text { é politica pública, mas ainda é um desafio sua implementação, } \\
\text { pois vai além da matricula e busca oferecer uma educação de } \\
\text { qualidade. Ahnos comAHSD enquanto PAEE tem recebido } \\
\text { pouca ou nenhuma atenção na educação inchusiva desde ao } \\
\text { ensino básico até o nivel superior. }\end{array}$ & $\begin{array}{l}\text { Não hả consenso na teminologia sobre AHSDentre os } \\
\text { pesquisadores do assunto. A legislação utiliza AHSD. O ahuno } \\
\text { AHSD faz parte do PAEE com direito a atendimento } \\
\text { especializado do inicio da escolarização até a universidade, } \\
\text { ainda que esse direito ainda falte ser realmente efetivado. }\end{array}$ \\
\hline (CALLEGARI, 2019) & Qualitativo & 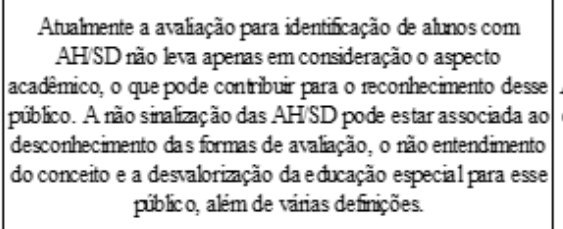 & $\begin{array}{l}\text { A produção de instrumentos confiáveis em sinalizar e identificar } \\
\text { esse público demonstra transparência e urgência na prática dos } \\
\text { pesquisadores. }\end{array}$ \\
\hline (OL VEIRA et al, 2021) & Qualiquantitativo & $\begin{array}{c}\text { Habilidades sociais contribui na qualidade e ef tividade no } \\
\text { relacionamento com o outro, mas não é suf́ciente para } \\
\text { competência social }\end{array}$ & $\begin{array}{l}\text { A competencia social se fazde uma leitura adequada do } \\
\text { ambiente social. Quanto maior o nivel de habilidades sociais } \\
\text { menos se observa comportamento problemático. }\end{array}$ \\
\hline $\begin{array}{l}\text { (WECHSLER e } \\
\text { SUAREZ 2016) }\end{array}$ & Qualitation & $\begin{array}{l}\text { Professor recém- formados não se sentem preparados para as } \\
\text { demandas de ensino, da dinersidade. }\end{array}$ & $\begin{array}{l}\text { Professor recém-formado não estão preparados para lidar com } \\
\text { ahmos com caracteristicas de AHSD. } \\
\end{array}$ \\
\hline (OLVERA et al, 2020) & Qualiquantitativo & $\begin{array}{l}\text { A AHSD é comtemplada por legislação e isso signnifica que tem } \\
\text { direitos e garantias aos serviços especializados. A escola deve } \\
\text { inve stir no desenvolvimento interpessoal dos ahnos e dos } \\
\text { prof ssores, estes últimos por serem mediadores em sa a de } \\
\text { aula. O comportamento da criança é inffuenciado pelo ambiente } \\
\text { em que vive é mantida pelas contingências familiares. }\end{array}$ & $\begin{array}{l}\text { A escola tem que se preparar para atender a esse público em } \\
\text { suas necessidades e especificidades. A escola deve } \\
\text { implementar programas que visem desenvolver as habilidades } \\
\text { sociais dos ahnos. }\end{array}$ \\
\hline $\begin{array}{l}\text { (CUNHA e RONDII, } \\
\text { 2020) }\end{array}$ & Qualiquantitation & $\begin{array}{l}\vec{E} \text { preciso compreender as queixas dos estudantes com } \\
\text { indicadores de AHSD em ambient escolar para sohvionar } \\
\text { problemas que possam comprometer seu desenvolvimento. }\end{array}$ & $\begin{array}{c}\text { Entender as causas das queixas dos estudantes com } \mathrm{AH} / \mathrm{SD} \\
\text { pode ser útil a pais e professores para criar e planejar } \\
\text { estratégias de ensino. }\end{array}$ \\
\hline
\end{tabular}

Fontes: (WECHSLER e SUAREZ, 2016; CALLEGARI, 2019; CUNHA e RONDINI, 2020; MARTINS, 2020; OLVEIRA et al., 2020; PASIAN, 2020; REIS e CAPELLINI, 2020; OLVEIRA et al., 2021)

Pessoas com Altas Habilidades/Superdotação (AH/SD), segundo a Política Nacional de Educação Inclusiva, são aquelas que se caracterizam pelo alto desempenho e/ou elevada potencialidade em aspectos isolados ou combinados. Podem apresentar capacidade intelectual geral aumentada, aptidão acadêmica específica, pensamento 
criativo e/ou produtivo, capacidade de liderança, talento especial para as artes, capacidade psicomotora e grande envolvimento com a tarefa e aprendizagem em áreas de seu interesse (REMOLI et al., 2020). Estudos sobre esse tema demonstram a existência de mitos, que ainda perduram na sociedade, como o que diz que os AH/SD não necessitam de atendimento pois aprendem rápido. Isso dificulta a sua identificação e os deixa à margem nesse processo (FREITAS e FERREIRA, 2021). A presença de indicadores de $\mathrm{AH} / \mathrm{SD}$ aponta para a necessidade de atenção educacional especializada que respeite as suas particularidades e desenvolva a sua potencialidade, daí a necessidade de identificação, mas sem perder as características do desenvolvimento da infantil (OLIVEIRA, 2020).

No estado do Amapá esse atendimento é prestado, desde 2006, pelo Centro de Atividades de Altas Habilidades e Superdotação (CAAH/SD), por uma equipe multidisciplinar (GOVAP, 2016). O objetivo, atendendo a legislação, é orientar e dar apoio ao sistema de ensino para discentes com essas características detectadas (SEED, 2020).

A educação especial voltada para as AH/SD contém desafios como as necessidades cognitivas, sociais e emocionais e o combate a mitos relacionados aos discentes. Enfrentá-los requer do professor uma formação que o embase para tal, além de proporcionar espaços e materiais adequados para atender esse público. É necessário o desenvolvimento de técnicas para sua identificação e adequações necessárias para seu atendimento. A formação docente deve envolver procedimentos técnicos-metodológicos relacionados ao planejamento, deve envolver a relação professor/aluno e utilizar mediação de recursos didáticos (DRULIS e SALES, 2021). As escolas e os profissionais precisam estar preparados para intervirem para que as necessidades dos alunos sejam contempladas (SANTOS, 2020).

O sistema de ensino apresenta dificuldades para lidar com esse público. A falta de identificação de sua condição colabora para o não atendimento e valorização de suas necessidades (MARTELLI e MOREIRA, 2021). Uma possibilidade de atendimento no 
espaço escolar, que é considerado um local de aprendizado formal, com suas regras e exigências, é a presença de salas multifuncionais, onde o atendimento pode ser realizado individualmente ou em pequenos grupos, de acordo com as características de cada um, utilizando materiais e um planejamento condizente com o mesmo (ESPANHOL, 2020).

O termo AH/SD levanta a questão da identificação e o que é ser inteligente. Isso gera muitas discussões, com visões opostas: uma de uma pessoa feliz, segura, bemsucedida e adaptada. A outra de uma pessoa difícil, ansiosa, problemática e sensível. O que demonstra uma ausência de conhecimento sobre esse público. Esses alunos sofrem com a falta de identificação de sua condição, e isso acarreta $o$ não atendimento de suas necessidades educacionais e do desenvolvimento da sua potencialidade (MARTELLI e MOREIRA, 2021).

A tabela 6 mostra os resultados e conclusões dos artigos sobre o descritor "altas habilidades / superdotação e EPT" com método, autor e ano de cada artigo 
Tabela 6 - Resultados e conclusões dos artigos sobre o descritor "altas habilidades / superdotação e EPT" com método, autor e ano de cada artigo.

\begin{tabular}{|c|c|c|c|}
\hline AUTOR E ANO & $\begin{array}{c}\text { TIPODE } \\
\text { MÉTODO }\end{array}$ & RESULTADOS & CONCLUSÃO \\
\hline (BRUNO, 2020) & Qualitativo & $\begin{array}{l}\text { O Censo Escolar é o instrumento legal para registro dos ahunos } \\
\text { pelo MEC, mas não obriga os ahunos com necessidades } \\
\text { especificas a se declarar como tal, além da falta de informações } \\
\text { dos profissionais da educação, pais, ahmos além complexidade } \\
\text { da identificação das AHSD. Apesar de saber da existência } \\
\text { desses ahrnos os IFs alegam que não há profissionais ou tempo } \\
\text { para essa identificação e atendimento. }\end{array}$ & $\begin{array}{l}\text { Os profissionais mesmos formados na área de educação } \\
\text { inc husiva não se sentem preparados para atar com AH SD e } \\
\text { solicitamaux ilio á instihuções parceiras. Hả a necessidade de } \\
\text { estra tégias que subsidiem os profissionais dos IFs, ao } \\
\text { atendimento dos ahmos com AHSD, no seu percurso } \\
\text { formativo. }\end{array}$ \\
\hline $\begin{array}{c}\text { (ZAGO e RIBEIRO, } \\
2017)\end{array}$ & Qualitativo & $\begin{array}{c}\text { Hả de se considerar a importância do reconhecimento desses } \\
\text { ahnos par que se possa desenvoker suas habilidades de forma } \\
\text { plena, além de se realizar mais estudos sobre o tema. A } \\
\text { innisibilidade desses estudantes na instituição é fato devido a } \\
\text { dificuldade de identificação e o conhecimento sobre o tema } \\
\text { pelos profissionais da insturução. }\end{array}$ & $\begin{array}{l}\text { É fundamental que as instituicõos refiltam sobre o atendimento } \\
\text { desses ahnos visto que o processo de ensino e aprendizagem, } \\
\text { tem emcada um, suas particularidades. A educação inchusiva e } \\
\text { o AEE preconizados na legislação requerem que as instituxiços } \\
\text { repensem sus estruturas pra garantir esses serviços. }\end{array}$ \\
\hline $\begin{array}{l}\text { (VOLANTE et al, } \\
\text { 2021) }\end{array}$ & Qualitativo & $\begin{array}{c}\text { Com os avanços na legishação quanto ao acesso do PAFE } \\
\text { observa-se o crescimento nas matriculas desse público na rede } \\
\text { regular e na rede EPT. Mirtos professores na Rede EPT não } \\
\text { tiveram contato com conhecimentos de processos pedagógicos } \\
\text { obrigatórios em cursos de licenciatura e sobre educação } \\
\text { inchusiva, pois o minimo exigido para investidura no cargo é } \\
\text { graduação na área que atuará. }\end{array}$ & $\begin{array}{l}\text { Observa-se que o processo de formação docente ao que tudo } \\
\text { indica não acomparhh essa realidade de inchusão. É possivel } \\
\text { afrmar que a garantia de vagas para oPAEE não garante a } \\
\text { formação continuada para os docentes das IFs. }\end{array}$ \\
\hline $\begin{array}{l}\text { (MONTEIROe } \\
\text { PLÁADO, 2020) }\end{array}$ & Qualitativo & $\begin{array}{l}\text { Diferentes frmas de segregação marcam o sistema educacional } \\
\text { brasileiro mostrando uma dualidade na EPT não é difrente. O } \\
\text { ahno pode estar inerido na escola, mas exchuido do processo } \\
\text { educacional A capacidade de se colocar no hugar do outro } \\
\text { pode ser favorecida com a convivência de pessoas que sofrem } \\
\text { com a exchusão. }\end{array}$ & $\begin{array}{l}\text { A história da EPT demonstra uma filta de artic ulação entre } \\
\text { frmação geral e formação profissional O acolhimento é um } \\
\text { instrumento cata lisador das relações e vai em direção a uma } \\
\text { educação inchusiva de fato e pode favorecer o estudante da } \\
\text { EPT em suas especificidades. Se a EPT busca uma formação } \\
\text { humana plena, transformadora então a inchusão deve começa } \\
\text { por umambiente acolhedor e práticas inchusivas. }\end{array}$ \\
\hline $\begin{array}{l}\text { (OLIVEIRA e } \\
\text { FERRÃO, 2021) }\end{array}$ & Qualitativo & $\begin{array}{l}\text { A formação profissional, nos IFs, vô homem como um ser } \\
\text { integral e o trabatho como principio educativo visando } \\
\text { despertar um olhar critico e global }\end{array}$ & $\begin{array}{l}\text { As pessoas com deficiência que ingressamnos institutos } \\
\text { federais deem ser frmadas em sua integralidade. }\end{array}$ \\
\hline
\end{tabular}

Fontes: (ZAGO e RIBEIRO, 2017; BRUNO, 2020; MONTEIRO e PLÁCIDO, 2020; OLIVEIRA e FERRÃO, 2021; VOLANTE et al., 2021).

Os Institutos Federais (IFs) fazem parte da Rede Federal de Educação na modalidade de Educação Profissional e Tecnológica. A Educação Especial atua em todos os níveis e modalidades de ensino, seja pública ou privada, e essas instituições devem realizar adequações que permitam 0 acesso desse público ao ensino profissionalizante e ao mundo do trabalho. Neste contexto criou-se, nos IFs, o Núcleo de Atendimento às Pessoas com Necessidades Educacionais Específicas (NAPNE), que tem por missão articular estratégias que desenvolvam o ingresso, a permanência e a saída com êxito dos estudantes PAEE para o ensino superior e/ou para o mercado de trabalho (FRANCO e VILARONGA, 2021). 
Segundo o decreto ํo10502 de 30 de setembro de 2020, o NAPNE possui espaço nos IFs e passa a ser entendido como apoio e não obrigatoriamente como atendimento a esse público, enquanto continua sendo listado como recurso e serviço especializado. Esse núcleo tem como foco a comunidade estudantil, mas também orienta professores e conduz atividades que contribuam com a formação docente. Também auxilia os gestores a tomar decisões relacionadas a questões que envolvam o público da educação inclusiva (FRANCO e VILARONGA, 2021).

Muitos professores responsáveis por disciplinas técnicas da formação profissional ingressam no quadro docente dos IFs por concurso, mesmo sem a formação docente em licenciatura, devido a autorização legal que ampara e compara o saber técnico com ela. Essa falta de conhecimento pedagógico pode dificultar na criação de estratégias de ensino que visem garantir o direito dos estudantes PAEE. Nesse sentido o apoio fornecido pelos NAPNEs se destaca no contexto da Rede Profissional Tecnológica (FRANCO e VILARONGA, 2021). Essa falta de conhecimento pedagógico pode ser corrigida através de formação continuada dos docentes que poderá acontecer no seu local de trabalho ou em instituição de educação básica ou superior (SANTOS et al., 2020).

Ainda há um longo caminho a ser percorrido, pelos NAPNEs, para cumprir sua proposta de criação, visto que ainda há várias diferenças entre cada um deles. Houve avanços quanto à criação de uma cultura de convivência, respeito às diferenças, acessibilidade arquitetônica, e eliminação das barreiras atitudinais e educacionais por meio da educação. Ações para modernizar a acessibilidade em IFs mais antigos e a garantia dessa acessibilidade em novas construções exemplificam esses avanços (VILARONGA et al., 2021).

\section{CONCLUSÕES}

A inclusão é um processo que requer uma mudança de atitude em relação às pessoas que são consideradas diferentes e que, por muito tempo, foram separadas do convívio social, gerando prejuízo a elas. Isso pode ser observado no processo de RC: 105196

Disponível em: https://www.nucleodoconhecimento.com.br/educacao/habilidades-no-ensino 
aprendizagem e nas consequências emocionais que acometem o indivíduo. Essa situação começa a mudar, mas ainda há um longo caminho a ser percorrido.

$\mathrm{Na}$ educação esse movimento começa a ganhar espaço nas escolas, e a educação inclusiva se torna, devagar, uma realidade. Ainda assim, apesar de ser um começo, ainda é excludente, pois os discentes inseridos são igualados aos demais, o que não leva em conta suas particularidades, acarretando mais problemas do que soluções, reforçando preconceitos.

Nesse contexto as pessoas com indicadores de AH/SD sofrem dos mesmos problemas, com o agravante de serem considerados alunos sem dificuldade (e com facilidade) de aprendizagem. São deixados à margem demonstrando as fragilidades do sistema escolar em relação a eles. Materiais e metodologias adequadas para o desenvolvimento de seu potencial são ausentes ou frágeis. O processo de identificação para atendimento é falho e há desconhecimento da legislação vigente que norteia a educação especial.

O processo de ensino necessita de adequações de processos, de materiais e de formação adequada para todos os professores. $O$ acesso facilitado às informações sobre o público alvo da educação especial pode melhorar a identificação, o atendimento e tornar o processo de inclusão de discentes AH/SD mais concreto.

$\mathrm{Na}$ Educação Profissional os problemas quanto a identificação e atendimento desse público parece ser semelhante ao da escola regular. Com suas particularidades, ainda existe a necessidade das adequações curriculares e formação adequada dos professores, o que garantiria a permanência e a saída exitosa de seus cursos, preparando o aluno para um possível ingresso ao mundo do trabalho ou às universidades. O NAPNE parece exercer papel fundamental nesse processo, assim como os núcleos especializados nas outras modalidades de ensino. 
A condução de mais estudos e pesquisas sobre o público AH/SD, tanto na escola regular quanto nos institutos tecnológicos, parece ser necessária para uma melhoria na identificação e atendimento destes discentes.

\section{REFERÊNCIAS}

ALMEIDA, M. L.; MELO, D. C. F.; FRANÇA, M. G. Repercussão da política nacional de educação especial no Espírito Santo nos últimos dez anos. Educ. Pesqui., v. 45, p. 2019.

Disponível em:

https://www.scielo.br/j/ep/a/SRdF9dyLhBFP3bmsWdWgDbc/?format=pdf\&lang=pt >.

AMARAL, L. C. Pessoa com deficiência: inclusão, acessibilidade na sociedade contemporânea. LEGIS, v. 12, n. 1, p. 33-51, 2019. Disponível em: < https://revistas.unisuam.edu.br/index.php/legisaugustus/article/view/444/197 >.

BAPTISTA, C. R. Política pública, Educação Especial e escolarização no Brasil. Educ. Pesqui, v. 45, p. 1-19, 2019.

BELL-RODRÍGUEZ, R. F. Comprensión del ciclo para la inclusión educativa en la educación superior ecuatoriana. Revista Electrónica Educare (Educare Electronic Journal), v. 24, n. 1, p. 1-21, 2020.

BERTOLDE, F. Z.; LARCHERT, J. M. Pensando As Adaptações Curriculares Na Perspectiva Da Educação Especial. In: CASTRO, P. A. D. (Ed.). Educação como (re)existencia: Mudanças, conscientização e conhecimentos Campina Grande PB: Editora Realize, v.1, 2020. p.1312-1329.

BONNER, I. C. S.; GONÇALVES, M. J.; SOUZA, P. V. V. Tecnologia e revistas em quadrinhos no trabalho da inclusão. Humanidades \& Inovação, v. 8, n. 35, p. 229239, 2021.

BRASIL. LEI № 11.741, DE 16 DE JULHO DE 2008. CASA_CIVIL. Brasilia DF: Presidência da República 2008.

RC: 105196

Disponível em: https://www.nucleodoconhecimento.com.br/educacao/habilidades-no-ensino 
. LEI № 13.146, DE 6 DE JULHO DE 2015. SECRETARIA-GERAL. Brasilia DF: Presidência da República 2015.

BRUNO, G. S. N. Desafio escolar na EdcaçãoPofissional e Tecnológica: Estratégias de atuação com alunos com Altas Habiidades/Superdotação. In: SONZA, A. P. (Ed.). Afirmar : a inclusão e as diversidades no IFRS : ações e reflexões. Bento Gonçalves RS: IFRS, v.1, 2020. p.191-201.

CALLEGARI, B. Adaptação e evidencias de validade de conteúdos das escalas para avaliação das características comportamentais de estudantes com habilidades superiores. 2019. 152p. (Mestrao). UNESP, Bauru SP.

CAPES. Treinamento no uso do Portal de Periódicos. Brasilia DF, 2012. Disponível em: < https://www.fca.unesp.br/Home/Biblioteca/portal-capes.pdf >. Acesso em: 06 set 2021.

CASSEMIRO, M. F. P.; CAMPOS, R. H. F. Formação de Professores para a Educação Especial - Propostas de Helena Antipoff e seus Colaboradores na Fazenda do Rosário nos Anos de 1960. Revista Brasileira de Educação Especial, v. 25, n. 2, p. 337 354, 2019.

CNE/CEB. Resolução № 4, De 2 de Outubro de 2009. Brasília DF: MEC: 1-3 p. 2009.

COELHO, C. P.; SOARES, R. G.; ROEHRS, R. Visões Sobre Inclusão Escolar No Contexto De Educação Especial: PCN X BNCC. Revista Educação E Políticas Em Debate, v. 8, n. 2, p. 158-174, 2019.

CUNHA, V. A. B.; RONDINI, C. A. Queixas Escolares Apresentadas Por Estudantes Com Altas Habilidades / Superdotação: Relato Materno. Psicologia Escolar e Educacional, v. 24, p. 1-10, 2020.

DARUB, A. K. G. S.; SOARES, L. G. C.; K., S. P. Formação docente inicial e as discussões sobre a inclusão. Análise do currículo do curso de pedagogia de uma 
universidade pública da região norte do Brasil InterCambios. Dilemas y transiciones de la Educación Superior, v. 7, n. 1, p. 43 - 53, 2020.

DRULIS, P. B. L.; SALES, A. Organização Do Trabalho Didático Em Atendimento Às Altas Habilidades/Superdotação. REIN-Revista Educação Inclusiva, v. 5, n. 1, p. 1423, 2021.

ESPANHOL, F. C. S. Propostas de atividades em grupo para estudantes com altas habilidades/superdotação. Revista Diálogos e Perspectivas em Educação Especial, v. 7, n. 1, p. 23-36, 2020.

FAVERI, F. N. M.; HEINZLE, M. R. S. Habilidades/Superdotação: políticas visíveis na educação dos invisíveis. Revista Educação Especial, v. 32, p. 1-23, 2019.

FERREIRA, G. C.; TOMAN, A. Educação especial e inclusão: O que mostram as iniciativas de formação continuada? REDOC, v. 4, n. 3, p. 1-20, 2020.

FLEIRA, R. C.; FERNANDES, S. H. A. A. Ensinando Seus Pares: a inclusão de um aluno autista nas aulas de Matemática Bolema, v. 33, n. 64, p. 811-831, 2019.

FRANCO, A. B. M.; VILARONGA, C. A. R. O contexto da inclusão escolar nos Institutos Federais e no Ensino Médio integrado. Revista Cocar, v. 15, n. 33, p. 1 21, 2021.

FREITAS, K. R.; FERREIRA, S. P. O núcleo de atividades de altas habilidades/superdotação na perspectiva de uma psicóloga. Brazilian Journal of Development, v. 7, n. 2, p. 17217-17230, 2021.

FREITAS, M. C.; JACOB, R. N. F. Inclusão educacional de crianças com deficiências: notas do chão da escola Educ. Pesqui, v. 45, p. 1-20, 2019. 
GALHARDO, E. et al. Desempenho acadêmico e frequência dos estudantes ingressantes pelo Programa de Inclusão da UNESP. Avaliação, v. 25, n. 3, p. 701723, 2020.

GOVAP. Centro de Altas habilidades comemora 10 anos de implantação no Amapá. Macapá $\quad$ AP, $2016 . \quad$ Disponível em: < https://www.portal.ap.gov.br/noticia/1705/centro-de-altas-habilidades-comemora-10anos-de-implantacao-no-amapa >. Acesso em: 05 dez 2021.

IFRN. NAPNE - Núcleo de Atendimento às Pessoas com Necessidades Educacionais Especiais. Natal RN, 2021. Disponível em: < https://portal. ifrn.edu.br/campus/natalcentral/nucleo-de-inclusao $>$. Acesso em: 06 set 2021.

JESUS, M. J. G.; OLIVEIRA, K. F.; PEDROSA, R. Educação inclusiva: O papel do professor e a intervenção do psicologo neste contexto. Revista Cefop Fapaz De Educação, Cultura, Ciência E Tecnologia, n. 1, p. 10-22, 2019.

JUNIOR, V. S. J.; CIA, F. Percepções dos familiares de estudantes público-alvo da Educação Especial sobre o Atendimento Educacional Especializado. Revista Educação Especial, v. 34, 2021.

LIMA, H. C. N. BNCC x PCN: Inclusão escolar no contexto de educação especial. IV CINTEDI. Campina Grande PB: UEPB: 1-12 p. 2020.

MANTOAN, M. T. E. Inclusão escolar : o que é? por quê? como fazer? São Paulo SP Moderna 2003. 51p. Disponível em: < https:/files.cercomp.ufg.br/weby/up/211/o/INCLUS\%C3\%83O-ESCOLARMariaTeresa-Egl\%C3\%A9r-Mantoan-Inclus\%C3\%A3o-Escolar.pdf >.

MANTOAN, M. T. E. Inclusão, diferença e deficiência: sentidos, deslocamentos, proposições. Inclusão Social, v. 10, n. 2, p. 37-46, 2017. Disponível em: < http://revista.ibict.br/inclusao/article/view/4030 >.

$\mathrm{RC}: 105196$

Disponível em: https://www.nucleodoconhecimento.com.br/educacao/habilidades-no-ensino 
MARTELLI, A. C. C. P. Políticas Educacionais Para Estudantes Com Altas Habilidades/Superdotação: Um Estudo Sobre A Transversalidade. 2017. 161p. (Mestrado). Universidade Federal do Paraná, Cuririba PR.

MARTELLI, A. C. C. P., E.; MOREIRA, L. C. A Transversalidade Das Políticas Educacionais Para Estudantes Com Altas Habilidades/Superdotação. Teoria E Prática Da Educação, v. 24, n. 1, p. 42-57, 2021.

MARTINS, B. A. Escala de Identificação de Precocidade e Indicadores de Altas Habilidades/Superdotação (EIPIAHS): um instrumento em construção. Revista Educação Especial, v. 33, p. 1-25, 2020.

MARTINS, B. A.; CHACON, M. C. M.; ALMEIDA, L. S. Altas Habilidades/Superdotação na formação de professores brasileiros e portugueses: Um estudo comparativo entre os casos da UNESP e da UMINHO. Educação em Revista, v. 36, p. 1-20, 2020.

MENDES, E. G. Sobre alunos "incluídos" ou "da inclusão": reflexões sobre o conceito de inclusão escolar. In: VICTOR, S. L.;VIEIRA, A. B., et al (Ed.). Educação especial inclusiva: Conceituações, medicalização e políticas. Campos dos Goytacazes RJ Brasil Multicultural., 2017. p.60-83.

MENDONÇA, L. D.; RODRIGUES, O. M. P. R.; CAPELLINI, V. L. M. F. Alunos com altas habilidades/superdotação: como se veem e como são vistos por seus pais e professores. Educar em Revista, v. 36, p. 1-22, 2020.

MONTEIRO, C. M. A.; PLÁCIDO, R. L. O acolhimento nas práticas educacionais inclusivas da EPT Educ. foco, v. 25, n. 3, p. 84-106, 2020.

NISTA-PICCOLO, V. L.; SILVA, Y. M. D.; MELLO, F. L. D. A inteligência humana e o cotidiano escolar. Série-Estudos, v. 23, n. 47, p. 27-41, 2018. Disponível em: < https://serieucdb.emnuvens.com.br/serie-estudos/article/view/1114/pdf >. 
OLIVEIRA, I. T. T.; FEITOSA, F. S.; MOTA, J. S. Inclusão Escolar De Alunos Com Necessidades Especiais: Desafios Da Prática Docente. Revista Humanidades e Inovação, v. 7, n. 8, p. 81-95, 2020.

OLIVEIRA, M. C. C. Revisão bibliográfica: A importância de medidas adequadas para o desenvolvimento de pessoas com altas habilidades/superdotação. IV CINTEDI. Campina Grande PB UEPB: 1-7 p. 2020.

OLIVEIRA, S. C. S.; FERRÃO, T. S. Os caminhos da Inclusão das pessoas com deficiência: a evolução até a educação profissional e tecnológica da Rede Federal. Research, Society and Development, v. 10, n. 12, p. e504101220702, 2021.

OLVEIRA, A. P. et al. Habilidades Sociais e Problemas de Comportamento de Crianças com Altas Habilidades/Superdotação. Psicologia: Ciência e Profissão, v. 41, p. 1-17, 2021.

OlVEIRA, A. P.; F;., C. R. M.; RODRIGUES, O. M. P. R. Altas Habilidades/Superdotação: Intervenção em Habilidades Sociais com Estudantes, Pais/Responsáveis e Professoras Revista Brasileira de Educação Especial, v. 26, n. 1, p. 125-142, 2020.

PASIAN, M. S. Alunos com Alts Habilidades /Superdotação na Educação Especial: Terminologia e Origem. Cadernos da Fucamp, v. 19, n. 42, p. 48-55, 2020.

PÉREZ, S. G. P. A identificação das altas habilidades sob uma perspectiva multidimensional. Revista Educação Especial, v. 22, n. 35, p. 299-328, 2009.

PLETSCH, M. D.; SOUZA, F. F.; ORLEANS, L. F. A. A diferenciação curricular e o desenho universal na aprendizagem como princípios para a inclusão escolar. Revista Educação E Cultura Contemporânea, v. 14, p. 264-261, 2017. 
RECH, A. J. D.; NEGRINI, T. Formação de professores e altas habilidades/superdotação: um caminho ainda em construção. RIAEE-Revista IberoAmericana de Estudos em Educação, v. 14, n. 2, p. 485-498, 2019.

REIS, V. L.; CAPELLINI, V. L. M. F. Altas habilidades/superdotação e criatividade em estudantes do ensino médio: identificação por instrumentos de auto avaliação Revista Ibero-Americana de Criatividade e Inovação, v. 1, n. 2, p. 107-122, 2020.

REMOLI, T. C. et al. Programa para desenvolvimento da criatividade a alunos com e sem altas habilidades/superdotação. Psic. da Ed., v. 50, p. 73-83, 2020.

RODRIGUES, T. D. et al. Compreensões sobre Educação no Campo no âmbito da Educação Inclusiva e da Educação Matemática: o contexto de duas pesquisas. Boletim GEPEM, n. 76, p. 170 - 183, 2020.

SALVINI, R. R. et al. Avaliação do Impacto do Atendimento Educacional Especializado (AEE) sobre a Defasagem Escolar dos Alunos da Educação Especial. Estudos Econômicos v. 49, n. 3, p. 539 - 568, 2019.

SANTOS, D. V. G.; FERRETE, A. A. S. S.; SANTOS, L. A. M. Análise Da Produção Científica Acerca Da Formação Continuada De Docentes Dos Institutos Federais. Revista Brasileira Da Educação Profissional E Tecnológica, v. 1, p. 1 -19, 2020.

SANTOS, K. V. G. Práticas Pedagógicas De Professores Das Salas De Recursos De Altas Habilidades/Superdotação Do Distrito Federal Segundo A Teoria De Joseph Renzulli. 2020. 152p. (Mestrado). Universidade De Brasília, Brasília DF.

SANTOS, V. P.; SANTOS, A. R. Relação Entre A Distorção Idade-Série Nas Escolas Do Campo E As Políticas De Avaliação. Revista de Estudos em Educação e Diversidade, v. 1, n. 2, p. 166-184, 2020. 
SARDAGNA, H. V.; FROZZA, T. F. Narrativas e Práticas de Governamentalidade: A Perspectiva do Docente sobre o aluno com deficiência. Educação em Revista, v. 35, p. 1-23, 2019.

SASSAKI, O. M. S.; SILVA, E. S. Inclusão escolar: um saber necessário à prática docente? Rev. NEaD-Unesp, v. 4, n. 1, p. 86-112, 2018.

SEED. NTE 28 Live recebe o Centro de Atividades em Altas Habilidades/ Superdotação do Amapá. Macapá ap, 2020. Disponível em: < http://portal.educacao.rs.gov.br/Main/Noticia/Visualizar/portalseduc/NTE-28-Liverecebe-o-Centro-de-Atividades-em-Altas-Habilidades-Superdotacao-do-Amapa-1 >. Acesso em: 05 dez 2021.

SILVA, M. M. P. Contexto Educacional da Criança Portadora de Necessidades Educativas Especiais: A Importância do Professor. Revista Saber Digital, v. 1, n. 1, p. 154-161, 2021.

SILVA, N. C.; CARVALHO, B. G. E. Compreendendo o Processo de Inclusão Escolar no Brasil na Perspectiva dos Professores: uma Revisão Integrativa. Rev. Bras. Ed. Esp., v. 23, n. 2, p. 293-308, 2017.

STREIECHEN, E. M.; KRAUSER-LENKE, C.; CRUZ, G.C. Análise do percurso escolar de um estudante com altas habilidades em um contexto familiar multilíngue: um estudo de caso. Revista Brasileira de Educação, v. 25, p. 1-18, 2020.

VILARONGA, C. A. R. et al. Inclusão escolar e atuação dos Núcleos de Apoio às Pessoas com Necessidades Educacionais Específicas no Instituto Federal de São Paulo. Revista Brasileira de Estudos Pedagógicos, v. 102, p. 283-307, 2021.

VOLANTE, D. P.; COSTA, L. U.; CORDEIRO, U. P. R. L. A Rede EPT na perspectiva inclusiva: uma revisão sistemática da literatura sobre formação continuada docente. Cadernos de Aplicação, v. 34, n. 2, p. 1-23, 2021. 
WECHSLER, S. M.; SUAREZ, J. T. Percepção de professores em cursos de formação sobre Talentos/superdotação. Revista de Psicología (PUCP), v. 34, n. 1, p. 39 60, 2016.

WEIZENMANN, L. S.; PEZZI, F. A. S.; ZANON, R. B. Inclusão Escolar E Autismo: Sentimentos E Práticas Docentes. Psicologia Escolar e Educacional, v. 24, p. 18, 2020.

ZAGO, C. R.; RIBEIRO, E. A. W. Altas habilidades/superdotação e o atendimento educacional especializado na educação profissional, técnica e tecnológica: desafios e perspectivas. Revista Dynamis, v. 23, n. 1, p. 95-111, 2017.

ZERBATO, A. P.; MENDES, E. G. Desenho universal para a aprendizagem como estratégia de inclusão escola. Educação Unisinos v. 22, n. 2, p. 147-155, 2018.

Enviado: Janeiro, 2022.

Aprovado: Janeiro, 2022. 